\title{
ON DIFFERENTIABILITY OF A CLASS OF ORTHOGONALLY INVARIANT FUNCTIONS ON SEVERAL OPERATOR VARIABLES
}

\author{
TiAnPEI JiAng AND HRISTO SENDOV
}

Abstract. In this work, we study a connection between two classes of orthogonally invariant functions. Both types of functions are defined on $S^{n_{1}} \times \ldots \times S^{n_{k}}$. The functions in the first

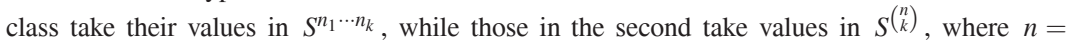
$n_{1}+\cdots+n_{k}$. Here, $S^{n}$ denotes the set of all $n \times n$ symmetric matrices. Using that connection we establish various smoothness properties of the functions in the first class, using analogous known results about the functions in the second class.

Mathematics subject classification (2010): Primary 15A18, 47A56, 49R50, Secondary 05A05, 47A75.

\section{REFERENCES}

[1] B. Ames And H. Sendov, Derivatives of compound matrix valued functions, J. Math. Anal. Appl. 433 (2016), pp. 1459-1485.

[2] H. ARAKi And F. HANSEn, Jensen's operator inequality for functions of several variables, Proc. Amer. Math. Soc. 128 (2000), pp. 2075-2084.

[3] J. AuJla, Matrix convexity of functions of two variables, Linear Algebra Appl. 194 (1993), pp. 149160.

[4] R. Bhatia, Matrix analysis, vol. 169, Springer Science \& Business Media, 2013.

[5] M. FIEDLER, Additive compound matrices and an inequality for eigenvalues of symmetric stochastic matrices, Czechoslovak Math. J. 24 (1974), pp. 392-402.

[6] F. Hansen, Operator convex functions of several variables, Publ. Res. Inst. Math. Sci. 33 (1997), pp. $443-463$.

[7] F. HAnsen, Operator monotone functions of several variables, Math. Inequal. Appl. 6 (2003), pp. 17.

[8] T. Jiang, M. Mousavi, And S. Sendov, On the analyticity of $k$-isotropic functions, Submitted, (2017).

[9] A. KorÁnyi, On some classes of analytic functions of several variables, Trans. Amer. Math. Soc. (1961), pp. 520-554.

[10] S. Mousavi And H. Sendov, A unified approach to spectral and isotropic functions, Submitted, (2016).

[11] M. Singh And H. VAsudeva, Monotone matrix functions of two variables, Linear Algebra Appl. 328 (2001), pp. 131-152.

[12] Z. Zhang, Some operator convex functions of several variables, Linear Algebra Appl. 463 (2014), pp. 1-9. 